

\title{
Grazing-Incidence La/B-Based Multilayer Mirrors for 6.x nm Wavelength
}

D S Kuznetsov, A E Yakshin, J M Sturm, F. Bijkerk

\section{To cite this version:}

D S Kuznetsov, A E Yakshin, J M Sturm, F. Bijkerk. Grazing-Incidence La/B-Based Multilayer Mirrors for 6.x nm Wavelength. Journal of Nanoscience and Nanotechnology, 2019, 19 (1), pp.585 592. 10.1166/jnn.2019.16476 . hal-01909417

\section{HAL Id: hal-01909417 https://hal.science/hal-01909417}

Submitted on 21 Nov 2018

HAL is a multi-disciplinary open access archive for the deposit and dissemination of scientific research documents, whether they are published or not. The documents may come from teaching and research institutions in France or abroad, or from public or private research centers.
L'archive ouverte pluridisciplinaire HAL, est destinée au dépôt et à la diffusion de documents scientifiques de niveau recherche, publiés ou non, émanant des établissements d'enseignement et de recherche français ou étrangers, des laboratoires publics ou privés. 


\title{
Grazing-Incidence La/B-Based Multilayer Mirrors for 6.x nm Wavelength
}

\author{
D. S. Kuznetsov*, A. E. Yakshin, J. M. Sturm, and F. Bijkerk \\ Industrial Focus Group XUV Optics, MESA + Institute for Nanotechnology, \\ University of Twente, 7500 AE Enschede, The Netherlands
}

\begin{abstract}
We studied a possibility of fabricating LaN/B grazing incidence multilayer mirrors for $6 . x \mathrm{~nm}$ radiation at a relatively large angle of incidence ( $\mathrm{AOI}=77^{\circ}$ off-normal). LaN/B multilayers with a periodicity of $15 \mathrm{~nm}$ were successfully fabricated. But when stored in air for one week they showed strong deterioration of the surface due to oxidation of the topmost LaN layers, even though the multilayer was capped with a thin B film. In a series of experiments with variable LaN thickness it was found that the $\mathrm{B}$ protective properties depend on the thickness of the underlying LaN layer. Based on these experiments a $15 \mathrm{~nm} \mathrm{LaN} / \mathrm{La} / \mathrm{B}$ multilayer with a passivation layer of only $0.4 \mathrm{~nm}$ of LaN was fabricated, which did not show any deterioration of the surface within a testing period of half a year. An initial reflectivity of $74.5 \%$ at $\approx 6.66 \mathrm{~nm}, \mathrm{AOI}=77^{\circ}$ off-normal was achieved, which was reduced by $0.5 \%$ absolute in half a year, due to contamination of the top $B$ layer.
\end{abstract}

Keywords: Grazing-Incidence, 6.x Multilayer, LaN/B, LaN/La/B, La Surface Nitridation, XUV Optics, EUV Optics.

\section{INTRODUCTION}

$\mathrm{La} / \mathrm{B}-$ based multilayers have a potential to be used as mirrors in EUV telescopes for space research, ${ }^{1,2}$ for $6 . x \mathrm{~nm}$ wavelength EUV lithography, ${ }^{3}$ and various other applications, for instance, optics for high-intensity free electron lasers $(\mathrm{FEL})^{4,5}$ or ultrasensitive analysis of materials by X-ray fluorescence. ${ }^{6}$ Recently, a significant improvement of the reflectivity at $6 . x \mathrm{~nm}$ was made using a special passivation scheme of $\mathrm{La}$ by nitrogen which resulted in about $64 \%$ reflectivity at near normal incidence $\left(\mathrm{AOI}=1.5^{\circ}\right.$ off-normal $\left.{ }^{7,8}\right)$. At the same time, some applications, for instance, the EIS-TIMER beamline ${ }^{9}$ at the FERMI@Elettra FEL ${ }^{10}$ also require mirrors for grazingincidence geometry. For this application, the authors fabricated ${ }^{11,12}$ a $4.8 \mathrm{~nm}$ period $\mathrm{La} / \mathrm{B}_{4} \mathrm{C}$ multilayer for $\mathrm{AOI}=45^{\circ}$ and achieved $54.4 \%$ reflectivity at $\approx 6.7 \mathrm{~nm}$. In Ref. [13] $66.5 \%$ was demonstrated for a $7.3 \mathrm{~nm}$ period $\mathrm{La} / \mathrm{B}$ stack at $\lambda \approx 6.7 \mathrm{~nm}$ and off-normal $\mathrm{AOI}=61.3^{\circ}$. In this work we study the possibility of fabricating a grazing incidence multilayer structure for a larger angle of incidence, which implies a larger period. Investigating the effect of this on the structure, reflectivity and environmental stability of the resulting multilayer is the aim of this work.

\footnotetext{
*Author to whom correspondence should be addressed.
}

Table I shows calculations ${ }^{14}$ of the maximum possible reflectivity (zero roughness of layers and no intermixing) for $\mathrm{La} / \mathrm{B}_{4} \mathrm{C}$ and $\mathrm{La} / \mathrm{B}$ multilayers in a range of different angles of incidence.

Elemental B-based multilayers show significantly higher peak reflectivity compared to $\mathrm{B}_{4} \mathrm{C}$-based multilayers. At $\mathrm{AOI}=77^{\circ}$, for instance, the gain by using elemental $\mathrm{B}$ is $16.6 \%$ (absolute). Due to that, $\mathrm{La} / \mathrm{B}$ is taken in our work as the basis for grazing-incidence $6 . x \mathrm{~nm}$ multilayers. Normal-incidence $6 . x \mathrm{~nm}$ LaN/B multilayers (with passivated La) showed higher reflectivity ${ }^{13}$ and better thermal stability ${ }^{18}$ than $\mathrm{La} / \mathrm{B}$, and therefore $\mathrm{LaN} / \mathrm{B}$ was the starting point for our experiments. A stack with a period of about $15 \mathrm{~nm}$ was chosen, reflecting at the off normal $\mathrm{AOI}=77^{\circ}$.

\section{EXPERIMENTAL DETAILS}

The deposition was performed by DC magnetron sputtering ${ }^{19}$ onto natively oxidized super-polished $\mathrm{Si}$ wafers (RMS roughness $\sim 0.2 \mathrm{~nm}$ ). The base pressure in the vacuum chamber was $1 \times 10^{-8}$ mbar. The highly reactive $\mathrm{La}$ target, as well as the $\mathrm{B}$ target, was cleaned before each deposition by pre-sputtering till stable discharge parameters (voltage, current) and stable deposition rate assessed by Quartz-Crystal Microbalances (QCM) 
Table I. Peak reflectivity for $\mathrm{La} / \mathrm{B}_{4} \mathrm{C}$ and $\mathrm{La} / \mathrm{B}$ multilayers calculated at different angle of incidence. Experimentally obtained optical constants of $\mathrm{La},{ }^{15} \mathrm{~B}^{16}$ and $\mathrm{B}_{4} \mathrm{C}^{17}$ were used. Number of periods and gamma-ratio (La-based layer thickness/bilayer thickness) were optimized for each multilayer. The value $\Delta$ indicates the absolute reflectance difference between $\mathrm{B}_{4} \mathrm{C}$ - and B-based multilayers.

\begin{tabular}{|c|c|c|c|}
\hline $\mathrm{AOI},{ }^{\circ}$ & $\mathrm{La} / \mathrm{B}_{4} \mathrm{C}, \%$ & $\mathrm{La} / \mathrm{B}, \%$ & $\Delta, \%$ (abs.) \\
\hline 77 & 62.6 & 79.2 & 16.6 \\
\hline 65 & 65.3 & 79.5 & 14.2 \\
\hline 45 & 65.9 & 79.6 & 13.7 \\
\hline
\end{tabular}

were reached. For storage outside of the vacuum chamber La target was kept in a vacuum-sealed package to prevent its strong oxidation. ${ }^{20}$ The depositions were done with $\mathrm{Ar}$ as a working gas, with the pressure being about $2 \times 10^{-3} \mathrm{mbar}$. The deposition rates were $0.03 \mathrm{~nm} / \mathrm{s}$ for $\mathrm{La}$ and $\mathrm{B}$, and $0.05 \mathrm{~nm} / \mathrm{s}$ for LaN. The conditions for the synthesis of the fully-passivated LaN are taken from our past work. ${ }^{8}$ La target was used both for $\mathrm{La}$ and $\mathrm{LaN}$ deposition, with LaN being deposited by reactive sputtering in $\mathrm{Ar}+\mathrm{N}_{2}$ mixture. All the multilayers had 15 periods and were covered by a B cap of the same thickness as in the stack (about $9 \mathrm{~nm}$ for $15 \mathrm{~nm}$ period). All specified thicknesses in the described experiments are the nominal values for thicknesses deposited based on calibrated deposition rates, uncompensated for any additional effects.

The surface composition of the samples was determined by non-destructive X-ray Photoelectron Spectroscopy (XPS), using a Thermo Scientific Theta Probe Instrument employing monochromatic $\mathrm{Al}-\mathrm{K} \alpha$ radiation. Since the XPS probing-depth is about $5-7 \mathrm{~nm},{ }^{21}$ and the top B layer (cap) is about $9 \mathrm{~nm}$, these measurements probed exclusively the top B layer. Distribution of the elements inside the stack was assessed by XPS depthprofiling implemented by ion etching $\left(\mathrm{Ar}^{+}, 0.5 \mathrm{keV}\right)$. XPS spot size (analyzed area) was about $400 \mu \mathrm{m}$, the take-off angle was varied to collect integrated signal in the range $\pm 30^{\circ}$ around average take-off angle $53^{\circ}$ with respect to surface normal.

For visual monitoring of the surface condition of the samples optical microscopy was employed, using a Nikon Eclipse ME600, in PC-controlled setup with NIS-Elements
D 3.10 as the imaging software. The latter allows programmed high frequency measurements of the same spot to monitor surface changes in real time.

For measurements of the surface roughness of the samples a Bruker Dimension Edge ${ }^{\mathrm{TM}}$ Atomic Force Microscope (AFM) was used with special probe for highresolution: Hi'Res-C14/Cr-Au by MikroMasch with spike radius about $1 \mathrm{~nm}$.

The period of the multilayers was extracted by analysis of Bragg peaks' positions at grazing incidence hard $\mathrm{X}$-ray reflectivity (GIXRR) curves, measured at a PANalytical Empyrean X-ray diffractometer $(\mathrm{Cu}-\mathrm{K} \alpha$ radiation, $\lambda \approx 0.154 \mathrm{~nm}$ ).

The soft X-ray $(6 . x \mathrm{~nm}$, at-wavelength) reflectivity $(R)$ of the multilayers was measured at Physikalisch Technische Bundesanstalt (PTB) ${ }^{22}$ using the synchrotron radiation of the BESSY storage ring in Berlin, Germany. The measurements were conducted for the as-deposited structures and after storage in order to assess the degradation of the structure as well as the influence of the surface contamination. The influence of contaminants on $6 . x \mathrm{~nm}$ $R$ was estimated with IMD software ${ }^{14}$ with an input from the XPS measurements and suggesting a certain layer model of the top part of the stack. To reconstruct the multilayer structure a fit of at-wavelength GIXRR (measured at $\lambda \approx 6.66 \mathrm{~nm}$ ) was implemented with the IMD software ${ }^{14}$ employing a model-dependent approach assuming an error-function form of the interface transition zones $\left(\sigma\right.$ roughness/diffuseness $\left.{ }^{14}\right)$. A differential evolution algorithm was used for fitting. ${ }^{23}$

\section{RESULTS AND DISCUSSION}

\subsection{LaN/B Multilayers}

Our initial materials choice for depositing grazing incidence mirrors was a LaN/B structure with a period of about $15 \mathrm{~nm}(6 \mathrm{~nm} \mathrm{LaN}$ and $9 \mathrm{~nm} \mathrm{~B})$.

However, after one week of storage of the deposited multilayer in air, circular-like defective zones were observed (Fig. 1(a)). Zooming into a single defective zone using an optical microscope (Fig. 1(b)) reveals numerous features inside the defective zone, which were determined by AFM to be elevations. According to the AFM (a)

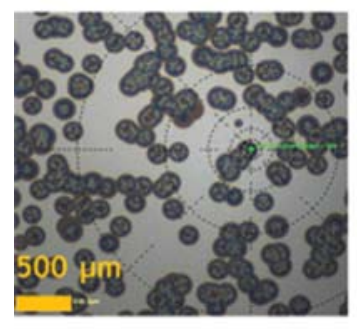

(b)

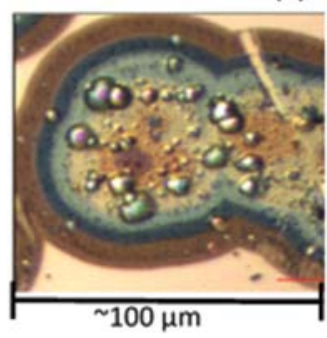

(c)

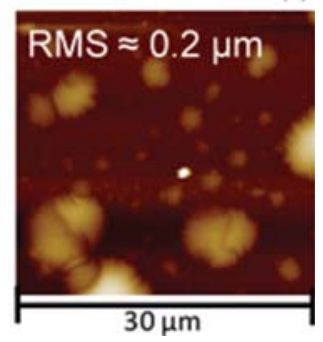

Figure 1. (a) Optical microscope view on the surface of LaN/B; (b) zoomed in optical microscopy view of a defective zone; (c) 2D AFM in a defective zone. 
measurement, the sizes of these elevations range from $\sim 1 \mu \mathrm{m}$ to $\sim 10 \mu \mathrm{m}$ in diameter and from $\sim 10 \mathrm{~nm}$ to $\sim 500 \mathrm{~nm}$ in height.

2D AFM measurements inside the defective zone and between the elevations (Fig. 1(c)) reveal severe roughening of the surface due to the presence of numerous features resulting in an RMS roughness of about $0.2 \mu \mathrm{m}$. Notably, the surface between the defects (bright areas on Fig. 1(a)) remains flat, with the RMS roughness of that area being about $0.3 \mathrm{~nm}$, like for the as-deposited structure. The XPS depth-profile in Figure 2 shows the distribution of the chemical elements in depth in a sample with the developed defects. The probing spot of XPS was $400 \mu \mathrm{m}$ and covered both defects and defect-free area shown on Figure 3. Note that after sputtering away the surface contamination, the atomic concentration of B reaches a value close to $100 \%$. This suggests that B layer is not oxidised. Furthermore this indicates that $\mathrm{B}$ is not delaminated in the defective areas, otherwise signal from the next layer would be visible. The presence of oxygen in the La-based layer directly under the B top layer is significant. The second from top La-based layer shows already a significantly reduced but still noticeable presence of oxygen. The optical view on the surface after the depth profiling (Fig. 3) was taken at exactly the same spot as shown in (Fig. 1(a)) within half a minute after finishing the depth-profiling. Notably, the defective zones are still visible at exactly the same positions as on the imaged structure before sputtering. However, no measurable signal of $\mathrm{La}, \mathrm{N}$ and $\mathrm{O}$ is present in the depth-profile after the first La-based layer (see Fig. 2, at around $4000 \mathrm{~s}$ etching time). This allows us to make an assumption on probable blister-nature of the elevations (Fig. 1). If 100-500 nm high elevations would be filled in with a solid material, the atomic concentrations of $\mathrm{La}, \mathrm{N}$ and $\mathrm{O}$ in XPS depth profile could not go to almost zero level in the B layer.

\subsection{B Protective Properties}

It is shown in the previous section that the LaN/B multilayers with about $6 \mathrm{~nm}$ thick LaN layers experience quick surface degradation when stored in air. To verify if the observed degradation is related to the presence of the $\mathrm{LaN}$

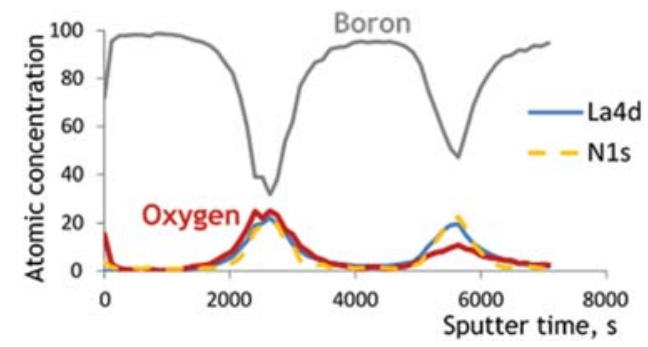

Figure 2. XPS depth-profile of LaN/B multilayer in one week after storage in air.

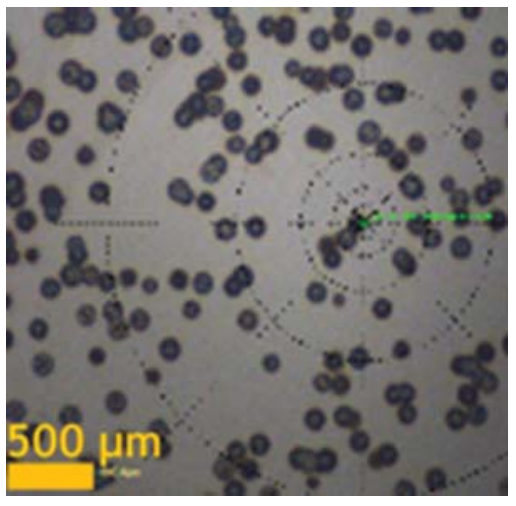

Figure 3. Optical microscope view on the surface of LaN/B multilayer after depth profiling (Fig. 2).

layer underneath the B capping layer, in the next deposition we replaced LaN with La. For that a $15 \mathrm{~nm}$-period $\mathrm{La} / \mathrm{B}$ multilayer was deposited. The latter shows no degradation of the surface in time even after half a year of storage in air. The surface RMS roughness stays at the as-deposited value of about $0.3 \mathrm{~nm}$. So, clearly, it is not the thickness of the top B layer that is responsible for the degradation of the $15 \mathrm{~nm}$ period LaN/B multilayers in this work. Based on this, it is proposed that the protective properties of the top B layer could depend on the material of the underlying layer. To check this suggestion as well as to exclude a possible influence of the multilayer underneath, a dedicated set of single-layer samples is fabricated. Their schematic structures are represented on Figures 4(a) and 5(a).

A relatively thin B cap was used to cover $30 \mathrm{~nm}$ thick $\mathrm{La}$ and LaN films to speed up the test. Initially the structures were covered with only $1.5 \mathrm{~nm} \mathrm{~B}$, but they both showed quick degradation. At the next step the structures were fabricated with $2 \mathrm{~nm} \mathrm{~B}$ and this proved to be a proper thickness for this test. For the B-on-La sample (Fig. 4(a)), after one week of storage no surface features were observed by optical microscopy (Fig. 4(b)). The surface kept the as-deposited roughness with RMS of about $0.3 \mathrm{~nm}$. The XPS depth-profile after 2 weeks of storage in air showed a typical value of about $5 \%$ of oxygen in $\mathrm{La}$, the level usually observed in La in every deposition in a vacuum of about $1 \times 10^{-8}$ mbar. On the contrary, the B-on-LaNsample qualitatively demonstrates similar degradation features as the LaN/B multilayer described above. In a few hours time of storage in air, circular-like defective zones appeared at the surface (Fig. 5(b)), and in-time the already existing defects were increasing in diameter while in the meanwhile new ones still appearing at various positions on the surface (Fig. 5(c)). At the initial stage the defects have an elevation at the centre as determined by AFM measurement (Fig. 5(e)). However, at a later stage, when the defects have grown in diameter enough to meet each other (Fig. 5(d)), instead of an elevation there is a pinhole 
(a)

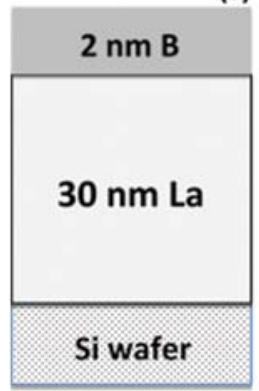

(b)



(c)

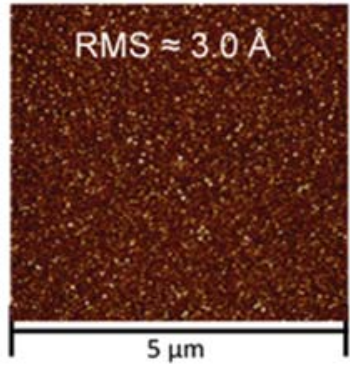

Figure 4. (a) Schematic structure of the B-on the La sample; (b) optical microscopy view of the La-sample after $>1$ week of storage; (c) 2D AFM of the La-sample surface after $>1$ week of storage.

formed about $40 \mathrm{~nm}$ deep, as shown on the cross-section of the 2D AFM measurement (Fig. 5(f)). This pinhole might explain the observed LaN/B stack oxidation through a few layers, however, when monitoring the LaN/B multilayer we did not observe any pinholes. Therefore, the precise mechanism of the development of the observed defects in the LaN/B multilayers has to be studied further. Importantly, our study did confirm that the protective properties of the top B layer depend on the underlying layer in case of a relatively thick (in our case $30 \mathrm{~nm}$ ) LaN layer.

According to our in situ studies of $\mathrm{La}$ and $\mathrm{LaN}$ growth, ${ }^{24}$ when $2 \mathrm{~nm}$ and thicker, it is found to have a reduced density compared to its bulk value. Therefore, we anticipated an increased porosity of the LaN layer, which facilitates penetration of oxygen species through the B top layer resulting in LaN oxidation. The suggested reason for $\mathrm{LaN}$ porosity is competing growth of two different LaN crystal structures, namely, wurtzite (WZ) and zincblende (ZB), resulting in so called stacking faults. Moreover, the crystal structure of LaN, with the layer being $2 \mathrm{~nm}$ and thicker, is very close (from crystallographic view) to the structure of lanthanum oxide $\left(\mathrm{La}_{2} \mathrm{O}_{3}\right)$, which might further facilitate oxidation of LaN. On the contrary, according to our results, La is found to have almost bulk density (therefore, highly unlikely porosity) and a dominant $\mathrm{NaCl}\left[\begin{array}{lll}1 & 1 & 1\end{array}\right]$ texture was revealed.

\subsection{La Surface Nitridation in Single Films}

As shown above, $15 \mathrm{~nm}$ period $\mathrm{La} / \mathrm{B}$ multilayers did not show any development of defects even after half a year storage in air. However, as found before for the normal-incidence $6 . x \mathrm{~nm}$ multilayers, $\mathrm{La} / \mathrm{B}$ multilayers demonstrated a significantly lower reflectivity at $6 . x \mathrm{~nm}$ compared to multilayers where the La layers were passivated to form LaN. ${ }^{13}$ This was shown to be due to the reduced chemical interaction at the interfaces and therefore (a)

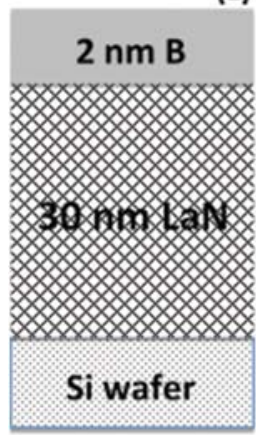

(b)

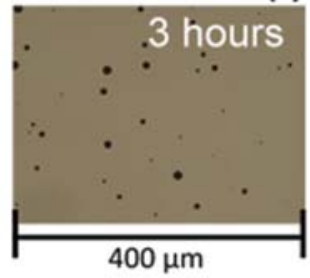

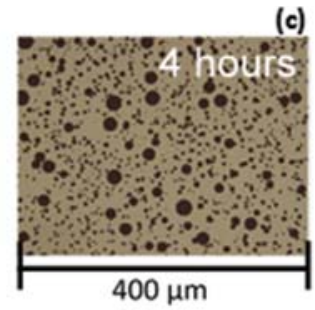

(c)



(e)

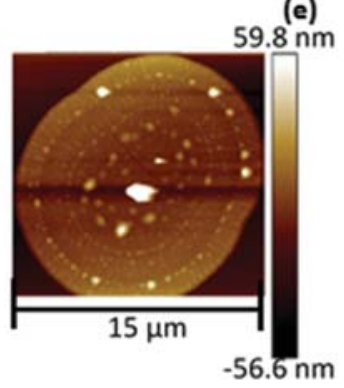

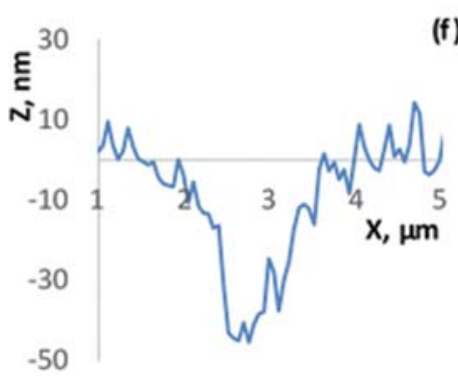

Figure 5. (a) Schematic structure of the B-on-LaN-sample; (b, c, d) optical microscopy pictures in 3, 4, 5 hours, respectively, after the deposition of the sample; (e) 2D AFM of defect in $3 \mathrm{~h}$ after deposition; (f) AFM cross-section in the centre of a defect in $5 \mathrm{~h}$ after deposition. 
(a)

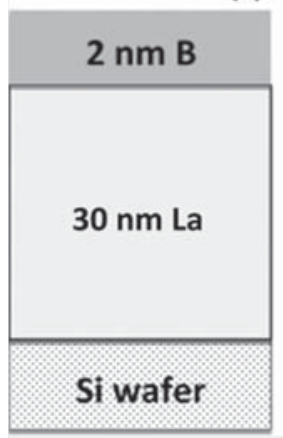

(b)



(c)

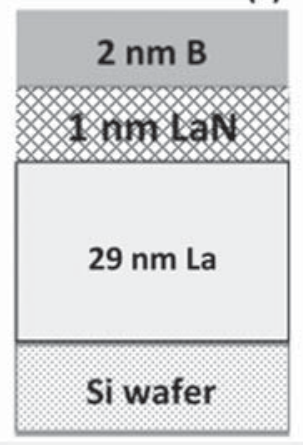

(d)

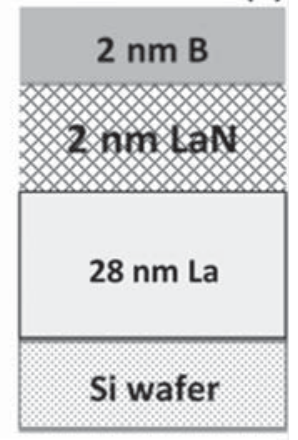

Figure 6. (a-d) Schematic picture of the composition of the samples with variable thickness of the LaN layers for a short life time test under storage in air. The sample on figure (a) is the same as the one represented on Figure 4(a).

higher optical contrast of the LaN/B stack. It was also shown in Ref. [7] that it is sufficient to passivate only the B-on-La interface to gain in reflectivity. Following this, as well as keeping in mind fast surface degradation when using a thick LaN layer, we design a structure where only the surface of La would be passivated, rather than the entire layer. As outlined above, B protective properties were found to depend on the material of the underlying layer. To examine the dependence of B/LaN/La thin film degradation on LaN thickness, a dedicated series of samples was fabricated with various thickness of the LaN layer as illustrated in Figures 6(a)-(d). Note that the total thickness of the La-containing layer $(\mathrm{La}+\mathrm{LaN})$ was kept $30 \mathrm{~nm}$ for all the samples. A B layer thickness of $2 \mathrm{~nm}$ is chosen, as it is found in this work to be the most suitable choice for a short life time test of the structures under storage in air.

Figures 7(a)-(d) shows optical microscopy views of the surfaces of the test samples after 1 week of storage in air. As seen, only in case of the sample with $2.0 \mathrm{~nm} \mathrm{LaN}$ layer some circular defects developed. The rest of the structures did not show any traces of degradation, like in the case of the structures based on pure La. This result suggests that the protective properties of the B layer do depend on the thickness of the underlying LaN layer. Therefore, when using passivation of La by nitrogen in the grazing incidence multilayer structures, it is necessary to keep the thickness of LaN to at least below $2.0 \mathrm{~nm}$.

\subsection{La Surface Nitridation in Multilayers}

Based on the results of the single layer tests, we fabricate two $15 \mathrm{~nm}$ period La/B-based multilayers, with only the top part of every La layer being nitrided, and one $\mathrm{La} / \mathrm{B}$ multilayer without La nitridation as the reference. Two different thicknesses of $\mathrm{LaN}$ are used, $0.4 \mathrm{~nm}$ and $1 \mathrm{~nm}$, to check which of the selected thicknesses is sufficient to completely prevent interaction of B with La on the B-onLa interface. Figure 8 shows the $6 . x \mathrm{~nm}$ reflectivity (the first Bragg peak) of these multilayers, measured at PTB. ${ }^{25}$

Both structures show a reflectivity gain of $1 \%$ absolute with respect to the $\mathrm{La} / \mathrm{B}$ multilayer (without $\mathrm{La}$ passivation). Notably, the achieved reflectivity is the same for both structures within the 0.05 uncertainty of the measurements. ${ }^{22}$ From this we conclude that even $0.4 \mathrm{~nm}$ of fully-saturated $\mathrm{LaN}^{8}$ is sufficient to passivate the B-on-La interface. The calculated ${ }^{14}$ theoretical maximum for an ideal structure (bulk densities, zero roughness's/intermixing, zero layer thickness errors) is included in Figure 8 as well. The theoretical maximum of about $79 \%$ leaves room for about $4.5 \%$ absolute possible gain for a further improved structure.

In order to reconstruct the structure of the obtained multilayer with $\mathrm{La}$ surface nitridation $(0.4 \mathrm{~nm} \mathrm{LaN})$, a simplified fitting model-based fitting of the measured $6 . x \mathrm{~nm}$ reflectivity is employed. The schematic representation of the model structure is shown in Figure 9(a). In our model, the $\mathrm{Si}$ wafer has RMS roughness of about $0.25 \mathrm{~nm}$ (a)
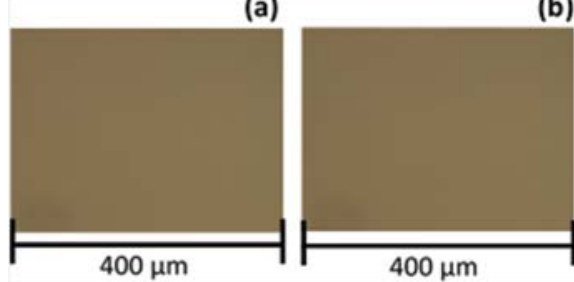

(b)

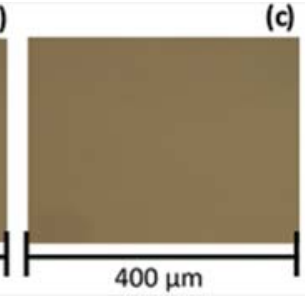

(c)

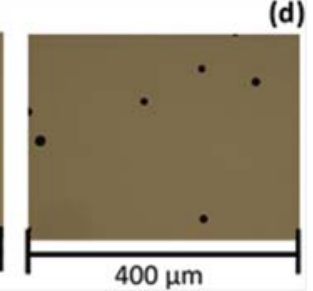

Figure 7. Optical microscopy view of surfaces of the samples from Figure 6 after 1 week storage in ambient atmosphere (air). 


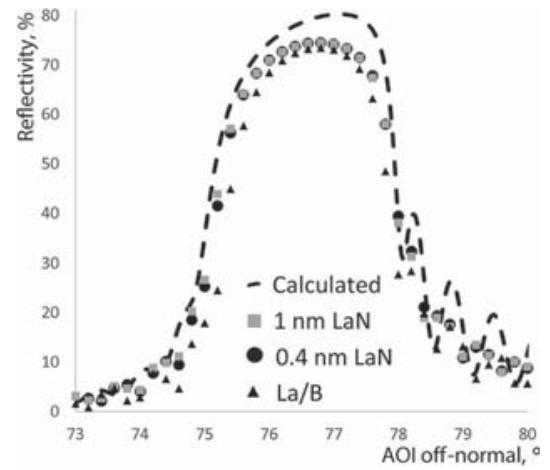

Figure 8. Measured soft $\mathrm{X}$-ray $(\lambda \approx 6.66 \mathrm{~nm})$ reflectivity (first order Bragg) for two $\mathrm{La} / \mathrm{B}$-based multilayers with $\mathrm{La}$ surface nitridation and $\mathrm{La} / \mathrm{B}$, calculated curve for an ideal optimized structure included.

according to the AFM measurements. The stack consists of alternating $\mathrm{La}$ and $\mathrm{B}$ layers. $\mathrm{LaN}$ is not included into the model because the optical constants of LaN are very close to La, with the difference in reflectance being not significant to determine parameters of LaN layers (including thickness, density, chemical composition, etc.). So the parameters of the LaN layer cannot be resolved in this analysis. Since the exact real densities of the B and La layers in the deposited stacks are not accurately known, we do not rely on the measured optical constants ${ }^{15,16}$ used in the initial calculations (Table I) but include the densities of $\mathrm{B}$ and $\mathrm{La}$ as the fitting parameters. The roughness/diffuseness $(\sigma)^{14}$ on the La-on-B and B-on-La interfaces is included in the fit with a composition-profile represented by an error-function in order to account for the interface zones. The top layer (contaminated upper part of $\mathrm{B}$ cap) is modelled as $\mathrm{B}_{x} \mathrm{O}_{y}$ in accordance with the results of XPS analysis done in 1 month after the deposition, with stoichiometry, density and thickness being fitted parameters. Simultaneously with that, the thickness of the underlying elemental (not contaminated) part of the B cap is fitted as well. An initial attempt of the fit was not successful when implemented without a diffusive interface between the contaminated top part of the top B layer and the underlying elemental $\mathrm{B}\left(\sigma\left(\mathrm{B}_{x} \mathrm{O}_{y}-\right.\right.$ on-B) in Fig. 9(a)). In this case, the modelled reflectivity peak in its top part is about at best $2 \%$ higher than the measured data. After introducing a diffused zone $\sigma\left(\mathrm{B}_{x} \mathrm{O}_{y^{-}}\right.$ on-B), the fitted Bragg peak on its top part is within $0.3 \%$ absolute of the experimental data. The final best fit is presented in Figure 9(b) together with the experimental data. Parameters as obtained by the fit to be taken into further consideration are stated in Figure 9(a). It is noted that the stoichiometry of the $\mathrm{B}_{2} \mathrm{O}_{2}$ obtained by the fit is within the under-stoichiometric (less rich in oxygen than $\mathrm{B}_{2} \mathrm{O}_{3}$ ) value concluded from the XPS analysis. The fitted densities of $\mathrm{B}$ and $\mathrm{La}$ are 2.0 and $5.2 \mathrm{~g} / \mathrm{cm}^{3}$, respectively.

Asymmetry of interfaces cannot be resolved by this analysis, i.e., values of $\sigma(\mathrm{B}-\mathrm{on}-\mathrm{La})$ and $\sigma(\mathrm{La}-\mathrm{on}-\mathrm{B})$ can be "interchanged" by applying intentional constraints on their ranges of allowed values and re-fitting the data. Still it is possible to assess the structural improvement done by the La surface nitridation. For this we model the structure only by varying the parameter $\sigma(\mathrm{B}-$-on-La).

As a result, the increase of reflectivity from $R=73.5 \%$ for the $\mathrm{La} / \mathrm{B}$ multilayer to $74.5 \%$ for the $\mathrm{LaN} / \mathrm{La} / \mathrm{B}$ multilayer could be modelled by a decrease of $\sigma(\mathrm{B}-\mathrm{on}-\mathrm{La})$ from $1.5 \mathrm{~nm}$ to $0.5 \mathrm{~nm}$. This means that the interface width of the B-on-La interface was effectively reduced by about $1 \mathrm{~nm}$. This improvement of the structure by La surface nitridation is indeed significant. The relatively small reflectivity gain of absolute $1 \%$ is explained by the relatively large period of the structure compared to the improved width of the interface, and by grazingincidence angle, at which reflectivity is less sensitive to interfacial/roughness effects compared to angles closer to normal incidence. Our calculations showed that the gain could reach e.g., 3-4\% (absolute) in case of a grazing incidence multilayer with a lower period, in particular, about 8-9 $\mathrm{nm}$.
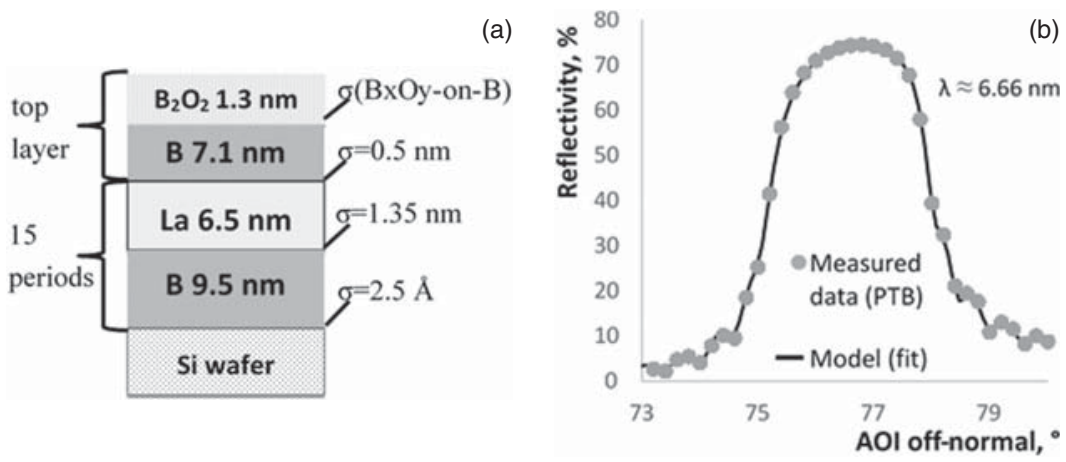

Figure 9. (a) A schematic structural model of the LaN/La/B multilayer (with La surface nitridation, $0.4 \mathrm{~nm} \mathrm{LaN}$ ); (b) the measured (circles) 6.x $\mathrm{nm}$ reflectivity of the $\mathrm{LaN} / \mathrm{La} / \mathrm{B}$ (La surface nitridation) multilayer and its best fit (line) employing the structural model on figure (a). 

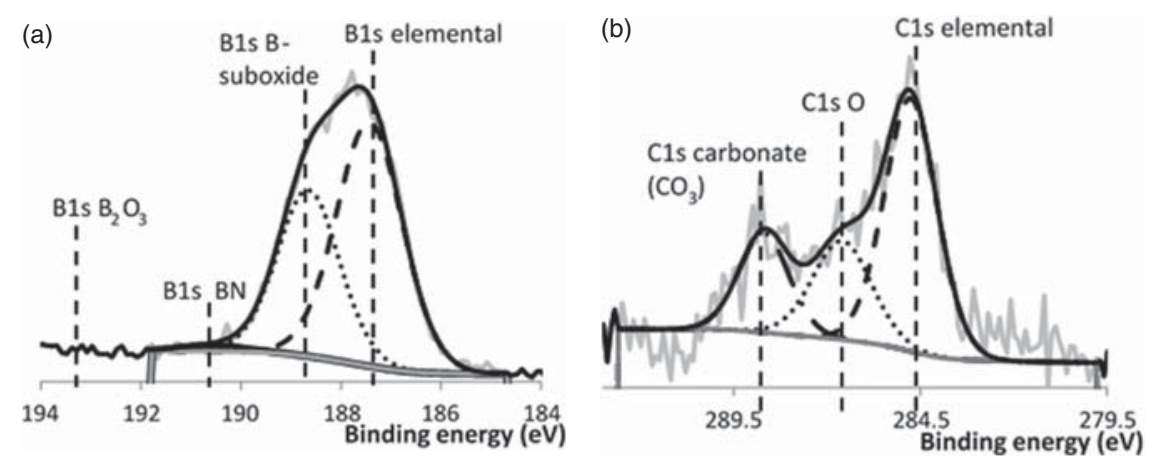

Figure 10. Fitted XPS B1s (a) $\mathrm{C} 1 s$ (b) spectra, measured as-introduced for the La/B-based multilayer with La surface nitridation after half a year storage in air.

\subsection{Stability of La/B Multilayers with La Surface Nitridation}

The long-term stability of $\mathrm{La} / \mathrm{B}$-based multilayers with $\mathrm{La}$ surface nitridation ( $\mathrm{LaN} 0.4 \mathrm{~nm}$ ) to storage in air was studied by various techniques in half a year after the deposition. Below these will be called aged multilayers. Optical microscopy revealed no defects or other features visible on the surface. The roughness of the surface did not change compared to the as-deposited samples, having an RMS value of $\approx 0.3 \mathrm{~nm}$ (measured by AFM). The XPS depthprofile for the aged multilayers showed a typical value of about $5 \%$ of oxygen in La, the level usually observed in $\mathrm{La}$ in every deposition in vacuum of about $1 \times 10^{-8}$ mbar. To assess possible surface contamination of the top B layer, non-destructive XPS measurements are done for the asdeposited sample and for the aged multilayer. For both samples, $\mathrm{O}$ and $\mathrm{C}$ elements were found. Since the binding energies of the fitted N1s and O1s XPS spectra could not be assigned unambiguously to any compound, we considered $\mathrm{B} 1 s$ and $\mathrm{C} 1 s$ XPS spectra to identify the surface contamination after storage. These spectra are shown in Figures 10(a) and (b). On the B1s spectrum (a), clear oxidation of $\mathrm{B}$ is observed, however no stoichiometric boron oxide $\left(\mathrm{B}_{2} \mathrm{O}_{3}\right)$ is found, expected at $193.1-193.7 \mathrm{eV}^{26}$ Only an under-stoichiometric (B-rich) oxide is observed. The $\mathrm{C} 1 s$-orbital spectrum (b) reveals the presence of elemental carbon (ascribed to hydrocarbons on the surface), an oxidised carbon with the stoichiometry of about 1:1 (C1s $\mathrm{O})$ and a rich in oxygen carbonate compound $\left(\mathrm{CO}_{3}\right)$. Quantification of the total $\mathrm{O} 1 s$ and $\mathrm{C} 1 s$ spectra shows similar percentages of both of them of about $13 \pm 1 \%$. There is also a small amount of BN present in XPS spectra originating from the interaction with air, which is also observed for the reference B layer samples. ${ }^{8}$ The measured percentages of contaminants after half a year of storage in air are totally related to the aging, since as-deposited samples do not show measurable by XPS amount of top layer contamination.

The $6 . x \mathrm{~nm}$ reflectivity is re-measured after the storage as well, and shows a reduced reflectivity by $0.5 \%$ (absolute) in the very top part of the Bragg peak. To be able to explain this drop in reflectivity by increased roughness/diffuseness at interfaces, the e.g. roughness parameter $\sigma(\mathrm{B}-\mathrm{on}-\mathrm{La})$ in the model would need to be increased from 0.5 to $1.3 \mathrm{~nm}$. However, in this case the FWHM would decrease from $2.895^{\circ}$ to $2.701^{\circ}$, so by as much as $0.2^{\circ}$. In reality the measured FWHM for the aged multilayer reduced from $2.895^{\circ}$ to $2.868^{\circ}$, so by only about 0.02 $0.03^{\circ}$. A similar behaviour is observed when involving the densities of the La and B layers and the gamma-ratio in the fitting procedure. This means that the reflectivity loss of the aged multilayer could most likely not be explained by an evolution of the internal structure. The remaining cause, which we have to consider, is surface contamination and oxidation of the top layer due to storage in air, as confirmed by the presence of hydrocarbons with $\mathrm{CO}$ and $\mathrm{CO}_{3}$ groups at the surface, as detected by XPS. All these factors are very difficult to describe in an unambiguous model. But, keeping in mind that in our simulations we observed a strong sensitivity of the very top part of the reflectivity peak to surface contamination, we consider surface contamination as the most likely reason for the observed reflectivity drop of $0.5 \%$ in the aged multilayers.

\section{SUMMARY}

We studied the possibility of fabricating LaN/B multilayers for $6 . x \mathrm{~nm}$ radiation at an $\mathrm{AOI}=77^{\circ}$ off-normal. $\mathrm{LaN} / \mathrm{B}$ multilayers of $15 \mathrm{~nm}$ period were successfully fabricated, but showed strong deterioration of the surface when stored in atmosphere, even though the multilayer was capped with a $9 \mathrm{~nm}$ thick B layer. It was shown by XPS that this deterioration is due to oxidation of at least two of the topmost LaN layers. In a series of short life time experiments on trilayer $\mathrm{LaN} / \mathrm{La} / \mathrm{B}$ films with variable $\mathrm{LaN}$ thicknesses, it was found that the $\mathrm{B}$ protective properties depend on the thickness of the underlying LaN layer. It was shown that for a thickness of this LaN less than $2 \mathrm{~nm}$ no deterioration of the surface observed. Thicker LaN is likely to have a higher porosity of the film, leading to enhanced oxygen diffusion. 
Based on these experiments, two $15 \mathrm{~nm} \mathrm{LaN} / \mathrm{La} / \mathrm{B}$ multilayers with a LaN passivation layer of only $0.4 \mathrm{~nm}$ and $1.0 \mathrm{~nm}$ were fabricated. The multilayers with $0.4 \mathrm{~nm} \mathrm{LaN}$ were chosen for temporal stability study and showed no deterioration of the surface within a testing period of half a year of storage in air. An initial reflectivity of $74.5 \%$ at $\approx 6.66 \mathrm{~nm}, \mathrm{AOI}=77^{\circ}$ off-normal was achieved for the as-deposited structure. This reflectivity reduced by $0.5 \%$ absolute in half a year of storage in air. IMD ${ }^{14}$ simulations suggest that this reflectivity loss entirely can be explained by contamination of the top B layer.

Acknowledgments: We acknowledge the support of the Industrial Focus Group XUV Optics at the MESA+Institute for Nanotechnology at the University of Twente, notably the industrial partners ASML, Carl Zeiss SMT, PANalytical, as well as the Province of Overijssel and the Foundation FOM (now part of NWO, the Netherlands Organisation for Scientific Research). Dr. Christian Laubis and colleagues at the Physikalisch-Technische Bundesanstalt (PTB) in Berlin are acknowledged for doing the reflectivity measurements.

\section{References and Notes}

1. D. Martinez-Galarce, P. Boerner, R. Soufli, J. Harvey, M. Bruner, J. Lemen, E. Gullikson, B. De Pontieu, N. Choi, M. FernandezPerea, N. Katz, S. Baker, E. Prast, S. Khatri, and J. Kong, 2nd International Conference on Space Technology (2011), p. 1.

2. K. Uji, I. Yoshikawa, K. Yoshioka, G. Murakami, and A. Yamazaki, Proceedings of SPIE 8528, 85281M (2012).

3. V. Banine, A. Yakunin, and D. Glushkov, International Workshop on Extreme Ultraviolet Sources, Dublin, Ireland (2010).

4. M. Barthelmess and S. Bajt, Applied Optics 50, 1610 (2011).

5. Y. Socol, G. N. Kulipanov, A. N. Matveenko, O. A. Shevchenko, and N. A. Vinokurov, Physical Review Accelerators and Beams 14, 040702 (2011).

6. M. K. Tiwari, K. J. S. Sawhney, and G. S. Lodha, Spectrochimica Acta Part B 65, 434 (2010).

7. D. S. Kuznetsov, A. E. Yakshin, J. M. Sturm, R. W. E. van de Kruijs, E. Louis, and F. Bijkerk, Optics Letters 40, 3778 (2015).
8. D. S. Kuznetsov, A. E. Yakshin, J. M. Sturm, R. W. E. van de Kruijs, E. Louis, and F. Bijkerk, AIP Advances 6, 115117 (2016).

9. F. Bencivenga and C. Masciovecchio, Nuclear Instruments and Methods in Physics Research Section A 606, 785 (2009).

10. E. Allaria, C. Callegari, D. Cocco, W. M. Fawley, M. Kiskinova, C. Masciovecchio, and F. Parmaigiani, New Journal of Physics 12, 075002 (2010)

11. P. Naujok, S. Yulin, A. Bianco, N. Mahne, N. Kaiser, and A. Tünnermann, Opt. Express 23, 4289 (2015)

12. N. Kaiser and H. K. Pulker, Optical interference coatings, Multilayer Coatings for EUV/Soft X-ray Mirrors, Springer-Verlag, Berlin Heidelberg (2003).

13. I. A. Makhotkin, E. Zoethout, R. W. E. van de Kruijs, S. N. Yakunin, E. Louis, A. M. Yakunin, V. Banine, S. Müllender, and F. Bijkerk, Opt. Express 21, 29894 (2013).

14. D. L. Windt, Computers in Physics 12, 360 (1998).

15. Yu. Uspenskii, J. Seely, N. Popov, I. Artioukov, A. Vinogradov, D. Windt, and B. Kjornrattanawanich, Proceedings of SPIE 5919, 59190S (2005).

16. M. Fernandez-Perea, J. I. Larruquert, J. A. Aznarez, J. A. Mendez, M. Vidal-Dasilva, E. Gullikson, A. Aquila, R. Soufli, and J. L. Fierro, Journal of the Optical Society of America 24, 3800 (2007).

17. R. Soufli, A. L. Aquila, F. Salmassi, M. Fernández-Perea, and E. M. Gullikson, Applied Optics 47, 4633 (2008).

18. S. L. Nyabero, R. W. E. van de Kruijs, A. E. Yakshin, I. A. Makhotkin, J. Bosgra, and F. Bijkerk, Journal of Micro/ Nanolithography, MEMS and MOEMS 13, 013014 (2014).

19. E. Louis, A. E. Yakshin, T. Tsarfati, and F. Bijkerk, Progress in Surface Science 86, 255 (2011).

20. N. N. Greenwood and A. Earnshaw, Chemistry of the Elements, Elsevier, Oxford, UK (1997).

21. S. Hüfner, Photoelectron Spectroscopy, Springer, Berlin, Germany (2003).

22. F. Scholze, C. Laubis, C. Buchholz, A. Fischer, S. Ploeger, H. Wagner, and G. Ulm, Proceedings of SPIE 5751, 749 (2005).

23. M. Björck, Journal of Applied Crystallography 44, 1198 (2011).

24. B. Krause, D. S. Kuznetsov, A. E. Yakshin, S. Ibrahimkutty, T. Baumbach, and F. Bijkerk, Journal of Applied Crystallography 51, 1013 (2018).

25. C. Laubis, A. Barboutis, M. Biel, C. Buchholz, B. Dubrau, A. Fischer, A. Hesse, J. Puls, C. Stadelhoff, V. Soltwisch, and F. Scholze, Proceedings of SPIE 8679, 867921 (2013).

26. A. V. Naumkin, A. Kraut-Vass, S. W. Gaarenstroom, and C. J. Powell, NIST X-ray Photoelectron Spectroscopy Database, National Institute of Standards and Technology, Gaithersburg MD (2000).

Received: 6 July 2017. Accepted: 5 June 2018. 